\title{
A Lógica da Ciência e o Falibilismo Epistemológico do Logical Syntax de Rudolf Carnap
}

\author{
The Logic of Science and the Epistemological \\ Fallibilism of Rudolf Carnap's Logical Syntax
}

\author{
Pedro Henrique Nogueira Pizzutti \\ Universidade Estadual de Londrina (UEL) \\ Orcid 0000-0003-3076-7379 \\ pedropizzutti@gmail.com
}

Gelson Liston

Universidade Estadual de Londrina (UEL)

Orcid 0000-0003-4963-9422

gelson@uel.br

Resumo: O presente artigo tem por objetivo analisar um importante momento de transformação na obra de Rudolf Carnap. Este momento diz respeito à publicação do livro The Logical Syntax of Language em 1934 e as modificações versam sobre a estrutura de análise lógica e as posições metateóricas do autor. Especificamente, no campo metodológico, Carnap desenvolve a sintaxe lógica enquanto estrutura de análise lógico-linguística e, a partir dela, elabora a Lógica da Ciência como o campo da Filosofia da Ciência e, no campo metateórico, substitui o fundacionismo metodológico do Aufbau pelo falibilismo epistemológico. Diante de tais mudanças, Coffa, uma referência fundamental do revisionismo carnapiano, alegou que o empirismo de Carnap, com a ascensão sintática e a perda do status de incorrigibilidade das 
sentenças protocolares, foi levado ao convencionalismo da base empírica e ao relativismo epistemológico. Deste modo, nosso objetivo neste artigo é apresentar uma interpretação consistente do Logical syntax, assim como avaliar e criticamente discutir a interpretação de Coffa em The semantic tradition from Kant to Carnap.

Palavras-chave: Logical Syntax; Lógica da Ciência; Falibilismo Epistemológico; Coffa.

Abstract: This article aims to analyze an important moment of transformation in the Rudolf Carnap's work. The moment we are concern about refers to the publication of The Logical Syntax of Language in 1934 and the modifications refers to author's logical analysis structure and metatheoretical positions. Specifically, in the methodological scope, Carnap develops the logical syntax as the structure of logic-linguistic analysis and elaborates the Logic of Science as the field of Philosophy of Science; in the metatheoretical scope, Carnap substitutes Aufbau's methodological foundationalism for epistemological fallibilism. In the face of such changes, Coffa, a central reference of carnapian revisionism, claimed that Carnap's empiricism with the syntactic ascension and the loss of protocol sentences incorrigibility status was led to the empirical basis' conventionality and epistemological relativism. Therefore, our aim in this article is to present a Logical syntax's consistent interpretation as well as to evaluate and critically discuss Coffa's interpretation in The semantic tradition from Kant to Carnap.

Keywords: Logical Syntax; Logic of Science; Epistemological Fallibilism; Coffa.

\section{Introdução}

Se, por um lado, Rudolf Carnap já foi visto como um autor dogmático pela tradição pós-positivista, especialmente sob a luz do amplamente difundido artigo "Dois dogmas do empirismo" (2011a) de Quine e pelo foco excessivo em interpretações estereotipadas do $A u f b a u^{1}$, por outro, podemos apresentar, e essa é nossa intenção aqui, uma interpretação consistente

$1 \quad$ Utilizamos o nome Aufbau por ser amplamente reconhecido na literatura, o título de nossa edição, entretanto, é The logical structure of the world (2005). 
com as posições de um autor tolerante em toda sua obra, que é marcada, por sua vez, pelo princípio de tolerância linguístico ${ }^{2}$, defesa da tese da unidade da ciência e pelo projeto de construção de uma estrutura para análise lógico-linguística que nunca pretendeu ser definitiva, mas efetiva e racional ${ }^{3}$.

Neste artigo, investigamos, sobretudo, um momento crucial de transformação no sistema de análise lógica e nas posições metateóricas de Carnap. O momento ao qual nos referimos remete-se à publicação da obra The logical syntax of language (1937a) [1934], onde, em contraste com o Aufbau [1928], Carnap, no campo metodológico, elabora a Lógica da Ciência e, com isso, "purifica" a Epistemologia dos seus elementos psicológicos ${ }^{5}$; ao mesmo tempo, no campo metateórico, Carnap abandona a ideia de incorrigibilidade das sentenças protocolares e, conse$2 \quad$ Como formulado explicitamente por Carnap, o princípio diz que: "não é nosso trabalho estabelecer proibições, mas chegar a convenções [...]. Em lógica, não há moral. Cada um é livre para construir sua própria lógica, isto é, sua própria forma de linguagem, como quiser. Tudo que é requerido deste é que, se a deseja discutir, deve expor seus métodos claramente e dar regras sintáticas [lógicas] ao invés de argumentos filosóficos" (CARNAP, 1937a, p. 51-52, itálico do autor). Tal princípio carnapiano é uma marca característica do seu trabalho e versa sobre a liberdade existente nas construções lógicas e linguísticas, teóricas e metateóricas. Além dessa formulação em Logical syntax, outra elaboração pode ser encontrada em "Empirismo, semântica e ontologia", 1975, p. 134.

3 Em geral, a interpretação clássica da obra carnapiana, representada por Quine, Ayer e Coffa, a separa em dois períodos: o fundacionista, caracterizado por um dogmatismo [Aufbau] e o antifundacionista, identificado com princípio de tolerância linguístico e com o falibilismo epistemológico [The logical syntax of language]. Todavia, esta interpretação acarretou dois problemas históricos, o primeiro, uma caracterização equivocada do período fundacionista como dogmático, o segundo, que advém do foco no período fundacionista, a caracterização de Carnap como um autor dogmático em geral. Nossa posição é a de que mesmo o período fundacionista não pode ser identificado com o dogmatismo, no entanto, como este não é o ponto de discussão deste artigo, o(a) leitor(a) pode encontrar uma análise deste debate em Carnap: lógica, linguagem e ciência (2015) de Gelson Liston.

$4 \quad$ Doravante, Logical syntax.

5 Carnap entendia a Epistemologia de sua época, incluído seu Aufbau, enquanto uma mistura ambígua de elementos lógicos e psicológicos. Esta posição carnapiana aparece no texto "Da epistemologia à lógica da ciência" (2012) que, originalmente, foi uma comunicação apresentada no Congrés International de Philosophie Scientifique, Paris, 1935. 
quentemente, modifica seu sistema do fundacionismo metodológico do Aufbau para o falibilismo epistemológico ${ }^{6}$.

Quanto à "purificação" da Epistemologia, ela representa um dos passos decisivos em direção à filosofia científica, isto é, à análise lógica do conhecimento científico, de suas sentenças, teorias e métodos. Pois, uma vez que Carnap (2012, p. 131) assume que seu Aufbau incorre em asserções de natureza psicológica e, além disso, sustenta a posição de que é tarefa exclusiva das ciências empíricas a elaboração das sentenças sintéticas, cabendo à Filosofia [Epistemologia] ${ }^{7}$ tão somente a investigação metalinguística dessas sentenças, é em Logical syntax que Carnap consegue, de maneira coerente com esta posição, sustentar seu projeto de análise lógica.

Tal projeto, ademais, representa a busca por formular de maneira precisa os problemas que eram preocupações centrais para o Círculo de Viena. Assim, dado que Carnap (1963, p. 55) considerava que as discussões acerca da teoria da verdade, das sentenças protocolares, da estrutura e justificação do conhecimento científico “...terminavam em questões de análise lógica da linguagem”, fazia-se necessária uma estrutura lógico-linguística adequada capaz de elaborar e investigar tais questões, sem cair nas indecidíveis disputas linguísticas que ocorriam por conta de a discussão estar expressa no modo material do falar. Com isto em vistas, o projeto de elaboração da Lógica da Ciência por meio da sintaxe lógica é a empreita de construção de uma estrutura capaz de investigar de maneira rigorosa os problemas em que estava envolta a filosofia da ciência do Empirismo Lógico.

Entretanto, apesar da relevância deste projeto, a plataforma sintática carnapiana não foi devidamente apreciada por críticos e colegas de trabalho por uma série de fatores. Como aponta Carus (2009, p. 34-36) em Carnap and twentieth-century

\footnotetext{
$6 \quad$ Esta mudança metateórica de Carnap é influenciada por Neurath e suas severas críticas ao status de incorrigibilidades das sentenças protocolares e ao fundacionismo, tais críticas podem ser encontradas em "Protocol sentences" (1959) de Neurath.

7 Como veremos, de Logical syntax em diante, a Epistemologia é substituída pela Lógica da Ciência.
} 
thought (2009), o primeiro fator é que, publicada em 1934, no contexto complicado que vivia a Europa com a ascensão do Nazismo, a obra não foi discutida pelos membros do Círculo, que se encontravam espalhados pela Europa e, até mesmo, fora dela. O segundo, é que o próprio Carnap acabou por incorporar, pouco tempo depois de sua publicação, uma plataforma semântica à sintática e passou a dedicar-se a investigações semânticas. O terceiro, é que a plataforma sintática desenvolvida em Logical syntax foi negligenciada por grande parte dos críticos, interlocutores e divulgares da obra carnapiana, o que fez com que a caricatura da obra de Carnap fosse construída majoritariamente sobre as posições elaboradas no $A u f b a u^{8}$.

Enquanto Carus destaca como Quine (2011a) e Ayer (1971) negligenciaram os constructos de Logical syntax, o mesmo não ocorre com Coffa (1991), a quem também atribuímos uma interpretação estereotipada da obra carnapiana e, em especial, do Logical syntax. No livro The semantic tradition from Kant to Carnap (1991), Coffa contempla tanto o desenvolvimento técnico da sintaxe lógica, quanto as posições metateóricas adotadas por Carnap em 1934, como, por exemplo, a posição antifundacionista consequente do abandono do status de incorrigibilidade das sentenças protocolares. Este último ponto é tratado no capítulo final de seu livro, onde uma das primeiras afirmações de Coffa é:

Por volta de 1930, um número de positivas [Carnap e Neurath] começaram a questionar a adequação do ponto de vista fundacionista que havia inspirado muito da filosofia tradicional. A nova atitude que esses "falibilistas" desenvolveram acerca da experiência foi bem-sucedida em apresentar uma imagem mais razoável do papel da certeza no conhecimento; mas, inesperadamente, também foi bem-sucedida em separar todos os links entre o conhecimento e a realidade, oferecendo uma epistemologia que diferia do idealismo apenas na retórica (COFFA, 1991, p. 354).

$8 \quad$ Quanto ao último ponto, Carus (2009, p. 34) detalha que o livro de Ayer Language, truth and logic (1971), publicado em 1936 e responsável pela divulgação das ideias do Empirismo Lógico no mundo de língua inglesa, ignora por completo a plataforma sintática. Não obstante, Carus ainda destaca que Quine em "Dois dogmas do empirismo", publicado em 1951, foi capaz de convencer o mundo de que ele tinha superado a teoria verificacionista de significado, uma posição que Carnap não defendia desde 1934. 
Já após uma ampla discussão acerca das temáticas das sentenças protocolares, teoria da verdade, estrutura e justificação do conhecimento científico ${ }^{9}$, que passa por autores como Schlick, Russell, Popper e Neurath, Coffa proclama que:

O novo caso dos positivistas [Carnap e Neurath] contra a certeza foi, agora consideramos, conclusivo. Na medida em que a crença na certeza se tornou mais fraca, o único elo de ligação universalmente reconhecido entre protocolos e fatos se tornou mais frouxo. Verdade e significado continuou, como sempre, uma espécie de encaixe com os protocolos, mas, agora, os protocolos não possuíam nenhuma conexão particular com a realidade. E, quando a forma dos protocolos se tornou uma questão de convenção, a verdade se tornou uma questão de encaixe entre sentenças e outras sentenças de forma convencionalmente especificáveis ou, de modo equivalente, um certo tipo de encaixe entre a classe de todas as sentenças aceitas [...]. No fim, o modo formal de Carnap e o desaparecimento da certeza transformou a teoria correspondentista [da verdade] na teoria coerentista e, portanto, levou o positivismo de seu inicial prescritivismo a uma posição radicalmente descritivista (COFFA, 1991, p. 371).

Esclarecendo, de maneira sucinta, a posição de Coffa, temos que em um sistema fundacionista, o conhecimento, as sentenças sintéticas, são estruturadas como se fossem um edifício. Neste edifício, as sentenças podem pertencer ao fundamento, sentenças que não dependem de outras para serem justificadas, ou, então, serem fundamentadas sobre as sentenças básicas. No sistema fundacionista do Aufbau, Carnap aloca a base do seu sistema no domínio autopsicológico e as sentenças básicas [sentenças protocolares] são enunciados na linguagem fenomenalista, isto é, descrições das experiências perceptuais individuais. Por característica, essas sentenças eram consideradas incorrigíveis e representavam uma relação "direta" com o mundo empírico [correspondência com os fatos], pois descreveriam aquilo que é dado na experiência. Desta maneira, ainda

9 De modo sumário, estas discussões foram centrais no Círculo de Viena através dos debates e pontos de vistas discordantes de seus membros principais, em especial, Schlick, Neurath e Carnap. Na questão da estrutura e justificação do conhecimento a contenda girava em torno do fundacionismo versus antifundacionismo; na temática da teoria da verdade, a questão estava em volta da teoria correspondentista versus teoria coerentista; e, por fim, a problemática das sentenças protocolares dizia respeito à forma e ao status epistemológico das sentenças básicas no sistema científico. Veremos, ao longo do artigo, como estas questões estavam interligas. 
que Carnap adote a base autopsicológica convencionalmente e não utilize termos como "certeza" no Aufbau, a tradição, e Coffa junto, considerou que a base adotada representava uma base empírica irrevisável pautada na certeza ${ }^{10}$.

Com isto posto, quando Carnap (1937a, p. 317) afirma, já em Logical syntax, que uma sentença empírica é comparada com as sentenças protocolare ${ }^{11}$ já estabelecidas e é rejeitada ou aceita com base nessa comparação e, além disso, que no caso de contradição no sistema, alterações devem ser feitas, mas que nenhuma sentença é intocável, seja ela lógica, matemática, lei ou protocolo, Coffa vê um abandono da certeza das sentenças básicas e, numa cadeia de consequências, considera que Carnap abandona o fundacionismo, a teoria correspondentista da verdade, e, por fim, transforma a própria questão da verdade das sentenças sintéticas em uma questão de convenção. Esta conclusão de Coffa faz com que ele afirme que Carnap rompe as ligações

10 Esta também é a interpretação de Quine (1989, p. 94) em "Epistemologia naturalizada" (1989), onde, comentando o "fracasso" do Aufbau, o autor afirma: "reconheceu-se serem vãs as esperanças de fundamentar, de modo solidamente lógico, a ciência natural sobre a experiência imediata. A busca de certeza cartesiana havia sido a motivação remota da epistemologia; no entanto, essa busca se revelou causa perdida".

11 Enquanto no Aufbau as sentenças protocolares pertenciam à linguagem fenomenalista, como, por exemplo, "aqui agora é verde", em Logical syntax, as sentenças protocolares pertencem à linguagem fisicalista, como, por exemplo, "há uma caneta verde sobre a mesa de estudos de Larissa às 11:00h do dia 01 de abril de 2020". Esta mudança ocorre por influência de Neurath e é uma consequência da adesão de Carnap à tese do fisicalismo para a tese da unidade da ciência. Este movimento, não obstante, é progressivo: em The unity of science (1995), de 1932, Carnap primeiro adere a tese de que a linguagem fiscalista é uma linguagem suficiente para a unidade da ciência, mas mantendo uma linguagem protocolar fenomenalista para propósitos de verificação; depois, no artigo "On protocol sentences" (1987), também de 1932, Carnap defende que é uma questão de escolha metodológica formular as sentenças protocolares na linguagem fenomenalista ou fiscalista, tendo ambas vantagens e desvantagens; já em Logical syntax, de 1934, a preferência de Carnap é por formular as sentenças protocolares na linguagem fiscalista. Por sua vez, Neurath sempre defendeu, em contraposição à formulação das sentenças protocolares na linguagem fenomenalista, que essas sentenças deveriam pertencer à linguagem fiscalista, como pode ser visto em "Physicalism" (1983a) e "Physicalism: the philosophy of the viennense circle" (1983b). 
existentes entre o conhecimento e a realidade, adotando, como última consequência, uma teoria coerentista da verdade.

Uma vez que adotada uma teoria coerentista da verdade, as sentenças são estruturadas como uma rede, um network, onde não há sentenças básicas irrevisáveis e a verdade das sentenças, em geral, consiste nas relações de coerência interna destas sentenças em um dado sistema linguístico. Por sua vez, Coffa (1991, p. 370) entende que um sistema de conhecimento baseado na teoria coerentista simplesmente retira a importância da experiência na justificação do conhecimento, torna a questão da verdade das sentenças sintéticas uma questão de convenção e, deste modo, acarreta no resultado trágico, no caso para o empirismo carnapiano, do relativismo epistemológico decorrente do convencionalismo da base empírica.

Neste artigo, defendemos que a interpretação de Coffa é equivocada e, portanto, compõe uma caricatura da obra carnapiana. Assim, a despeito do abandono do status epistemologicamente privilegiado das sentenças protocolares e do consequente abandono do fundacionismo, sustentamos que o empirismo de Carnap em Logical syntax mantém um componente objetivo, não-convencional. Este componente diz respeito ao teste empírico [confronto com os fatos], direto ou indireto, de qualquer que seja a sentença sintética, seja ela uma lei, seja ela uma sentença observacional básica. O convencionalismo de Carnap diz respeito às formas linguísticas [princípio de tolerância], como qual linguagem utilizaremos para descrever a ciência, assim como versa sobre questões metodológicas outras, como quando consideraremos uma sentença suficientemente confirmada pelas evidências. Todavia, esse convencionalismo carnapiano nunca define o conteúdo das sentenças sintéticas, cabendo aos cientistas tal definição. Desta forma, como Liston (2015, p. 125) destaca, "a escolha da base empírica, de fato, é convencional, mas tal convencionalismo não implica o abandono do correspondentismo" e, tampouco, o convencionalismo da base empírica implica um relativismo epistemológico no empirismo de Carnap. 
No entanto, mesmo que defendamos que Carnap mantém a todo custo um componente objetivo em seu empirismo, devemos salientar que em Logical syntax o autor não apresenta, explicitamente, uma teoria correspondentista da verdade. Tal fato pode dar, a princípio, alguma razão às críticas. Porém, Carnap não deixa de adotar uma teoria correspondentista para promover uma teoria coerentista, como a posição de Coffa proclama. Rigorosamente, Carnap não adota nenhuma teoria da verdade em Logical syntax, a explicação para isso está no projeto da sintaxe lógica. Definido como Carnap o faz, isto é, um método exclusivamente sintático, o autor toma os conceitos de "verdade" e "falsidade" como fora do escopo sintático e não trabalha com eles, o que o impede de adotar, explicitamente, qualquer teoria da verdade, sob pena de trair o projeto da Lógica da Ciência. No entanto, como argumentaremos, o aspecto correspondentista não é retirado do sistema, mas funciona em outro nível.

Diante destes fatores, apresentamos a seguinte hipótese de trabalho: uma leitura coerente com a base textual carnapiana, que evita os equívocos de interpretações estereotipadas, pode ser construída se as posições metateóricas carnapianas forem consideradas em estreita relação com a estrutura de análise lógica utilizada pelo autor e com o seu projeto de Lógica da Ciência. Valendo-nos dessa hipótese, o objetivo do presente artigo é apresentar uma interpretação do Logical syntax, com as posições metateóricas e com o projeto de análise lógica, que seja consistente com o texto e que justifique nossa contraposição à interpretação de Coffa.

\section{O Projeto de Logical Syntax}

Como citado, para Carnap (2012, p. 131), a Epistemologia de sua época era uma mistura ambígua de componentes lógicos e psicológicos, estando estes componentes misturados tanto nas construções dos membros do Círculo de Viena em geral, quanto em seu Aufbau. Tais elementos psicológicos apa- 
reciam quando a Epistemologia investigava coisas como, por exemplo, o "imediatamente dado", "cognições" e "conteúdo da consciência" ${ }^{2}$. Nestes casos, as inquirições, conforme a autocrítica de Carnap, pertenceriam à Psicologia, cujos métodos científicos de pesquisa deveriam ser empregados na investigação. Consequentemente, depurar a Epistemologia de seus elementos psicológicos constituía o passo necessário a ser dado em direção à filosofia científica, isto é, era necessário transformar a Epistemologia em uma análise lógica pura.

Com a depuração da Epistemologia em vistas, o projeto da sintaxe lógica é apresentado sustentando que a parte do trabalho filosófico que poderia ser considerada científica, já estando excluídas todas as questões empíricas que pertenceriam às ciências empíricas, seria a de análise lógica. Assim, o objetivo do Logical syntax é estabelecido como a construção de um sistema de conceitos, uma linguagem, por meio da qual a investigação e os resultados da análise seriam exatamente formulados. Deste modo, "a Filosofia é para ser substituída pela lógica da ciência - isto significa, pela análise lógica dos conceitos das ciências, pois a Lógica da Ciência não é outra coisa a não ser a sintaxe lógica da linguagem científica" (CARNAP, 1937a, p. xiii, itálico do autor).

Com a identificação da Lógica da Ciência com a sintaxe lógica, esta torna-se o campo da Filosofia da Ciência e sua investigação versa única e exclusivamente sobre a linguagem [científica]. Essa investigação é, deste modo, lógico-linguística e estruturada no plano sintático. Já a sintaxe lógica, propriamente dita, é definida por Carnap (1937a, p. 1) como a teoria

$12 \quad$ Na abertura do artigo "Pseudoproblemas na Filosofia" (1975b), que se apresenta como uma espécie de resumo das principais ideias do Aufbau, encontramos a seguinte passagem, que mostra justamente o que Carnap passou a considerar como uma mistura de elementos lógicos e psicológicos: "O objetivo da epistemologia é a formulação de um método para a justificação das cognições (Erkenntnisse). A epistemologia deve especificar como se pode justificar uma parte ostensiva do conhecimento, isto é, como se pode mostrar que essa parte é um conhecimento autêntico. Tal justificação, entretanto, não é absoluta, mas relativa; justifica-se o conteúdo de uma certa cognição relacionando-a aos conteúdos de outras cognições que se supõem serem válidas" (CARNAP, 1975b, p. 149). 
formal das formas linguísticas de uma linguagem qualquer que foi escolhida para análise ou, de outra forma, a sintaxe lógica visa o estabelecimento das regras formais que governam uma linguagem em conjunto com as consequências que se seguem dessas regras.

Pelo aspecto formal da investigação, a pesquisa sintática foca na parte da linguagem que possui as características de um cálculo e, assim sendo, as regras formais que são estabelecidas são de dois tipos, a saber, regras de formação e regras de transformação. Em sentido específico, seguindo Pereira (2013, p. 38), as regras de formação têm por objetivo determinar quais expressões constituem as sentenças elementares da linguagem e como é possível formar sentenças compostas a partir das elementares; já as regras de transformação visam determinar quando uma sentença é passível de dedução a partir de um conjunto de outras sentenças. Nesta esteira, Carnap estipula que:

Uma teoria, regra, definição, ou algo semelhante, é considerada formal quando nenhuma referência é feita ao significado dos símbolos (por exemplo, das palavras) ou ao sentido das expressões (por exemplo, das sentenças), mas são referidos simples e tão somente os tipos e a ordenação dos símbolos sobre os quais as expressões são construídas (CARNAP, 1937a, p. 1, itálico do autor).

Com essas diretrizes, a investigação sintática não faz nenhuma referência extralinguística e, para sua execução, são necessárias, ao menos a princípio, duas linguagens: a primeira delas é a linguagem que é o objeto de pesquisa, isto é, a linguagem para a qual a sintaxe lógica é formulada, essa é chamada por Carnap (1937a, p. 4), e pela tradição, de linguagem-objeto; a segunda, é a linguagem que é utilizada para estipular e se referir às formas sintáticas da linguagem-objeto e, enquanto Carnap a designa por linguagem-sintática, o nome consagrado na tradição é metalinguagem. No texto de Logical syntax, Carnap se vale, na qualidade de linguagem-objeto, de duas linguagens formalizadas que, abreviadas a partir de Linguagem I e II, são denominadas de L.I e L.II., enquanto como metalinguagem Carnap utiliza a língua inglesa [na edição em inglês] acrescida de símbolos góticos. 
Sem incidir nos detalhes técnicos das construções, os passos progressivos de Carnap em Logical syntax visam tanto superar dificuldades técnicas, quanto tornar o método forte $o$ suficiente para se trabalhar com a análise lógica da linguagem científica das ciências empíricas e exatas. Em resumo, com L.I, Carnap procura mostrar como é possível elaborar a metalinguagem de uma linguagem-objeto valendo-se apenas dos recursos expressivos da própria linguagem-objeto ${ }^{13}$. Com isto, Carnap tenta superar um possível regresso ao infinito de elaborações metasintáticas ${ }^{14}$. Já com L.II, Carnap busca, por meio de regras indefinidas de transformação, isto é, regras não recursivas, contornar as complicações impostas pelos teoremas da incom-

$13 \quad$ Para expressar a sintaxe de uma linguagem-objeto através dos recursos dela mesma, Carnap se vale do método de aritmetização de Gödel que, como Fajardo (2017, p. 146) explícita, “...consiste em associar fórmulas de uma linguagem de primeira ordem a números naturais, transformando relações metamatemáticas, como a de consequência sintática, em relações de números naturais". Consequentemente, "pelo teorema fundamental da aritmética, todo número natural positivo se decompõe de maneira única como produto de potências de números primos. Portanto, a numeração de Gödel nos dá uma correspondência um a um entre os números naturais e as sequências finitas (incluindo a vazia) de símbolos" (FAJARDO, 2017, p. 148). A ideia, basicamente, consiste em utilizar a aritmética para expressar a sintaxe da linguagem-objeto que, por sua vez, contém a aritmética, desta forma, como Trajan (2010, p. 196) aponta, "Carnap sabe que qualquer linguagem que tenha a seu dispor recursos para expressar a aritmética dos números naturais possui, por isso mesmo, recursos para expressar a (ou partes da) sintaxe lógica de que ela está tratando".

14 Outro objetivo de Carnap que pode ser ventilado era o desejo de provar não só que a posição de Wittgenstein no Tractatus logico-philosophicus (1922) acerca da impossibilidade da investigação metalinguística era equivocada, como não seria necessário recorrer a uma metalinguagem outra, isto é, a investigação poderia ser feita sobre uma linguagem', utilizando a própria linguagem'. Quanto a isso, é preciso dizer que Carnap enfrentou dificuldades técnicas sérias em Logical syntax, tendo de recorrer a metalinguagens mais ricas que a linguagem-objeto investigada para conseguir construir conceitos centrais, como o de analiticidade para L.II. Todavia, o(a) leitor(a) que se interessar pelo debate entre as ideais centrais do Logical syntax e do Tractatus logico-philosophicus acerca da investigação lógico-linguística, pode ver o artigo "From Wittgenstein's prison to the boundless ocean: Carnap's dream of Logical syntax" (2009) de Steve Awodey e A. W. Carus. 
pletude de Gödel ${ }^{15}$. Por fim, com as construções e discussões de L.I. e L.II. estabelecidas, Carnap se volta para o projeto de uma sintaxe geral aplicável a qualquer linguagem. Neste último desenvolvimento, merece destaque a possibilidade de regras físicas de transformação, o que permite que se inclua, entre as regras de transformação da linguagem, axiomas de teorias da Física, por exemplo. Com este itinerário, o método sintático se torna robusto o suficiente para lidar com a reconstrução racional de teorias científicas de acordo com a Received View ${ }^{16}$.

\subsection{A Lógica da Ciência e o Modo Formal do Discurso}

Ainda como dito, em Logical syntax, "a lógica da ciência é a sintaxe da linguagem da ciência” (CARNAP, 1937a, p. 315). Identificada com a sintaxe lógica, Carnap (1937a, p. 280-281) assevera que sob o termo de "Lógica da Ciência" encontram-se questões de análise lógica das ciências especiais em específico e da ciência como um todo, assim como questões que usualmente eram tratadas pela Epistemologia, como aquelas acerca da justificação racional do conhecimento científico. Deste modo, Carnap acredita que a Lógica da Ciência enquanto sintaxe lógica é capaz

15 Teorema 1: Se Té uma teoria de primeira ordem recursiva, consistente e capaz de expressar a aritmética, então $T$ é incompleta (FAJARDO, 2017, p. 149).

Teorema 2: Se $T$ é uma teoria de primeira ordem recursiva, consistente e capaz de expressar a aritmética, então $T$ não pode provar sua própria consistência (FAJARDO, 2017, p. 152).

Tais teoremas implicam que qualquer sistema axiomático recursivo, isto é, sintático recursivo, não pode ser completo e consistente ao mesmo tempo. Ou seja, a classe de sentenças verdadeiras logicamente [analíticas] não pode ser completamente demonstrada em sistemas sintáticos recursivos, sob pena de incorrer em contradições. Por isso, o esforço de Carnap em construir uma linguagem sintática que se vale de regras não-recursivas de transformação.

16 Uma introdução à Received View é encontrada em "A visão 'ortodoxa' de teorias: comentários para defesa assim como para crítica” (2004) de Herbert Feigl. De modo sumário, seguindo as indicações de Feigl, na Received View as teorias são reconstruídas como sistemas axiomáticos que, em um primeiro momento, não possuem interpretação empírica. Enquanto não interpretados, esses sistemas de postulados estão "pairando" acima do plano dos fatos e é somente por meio de regras de correspondência, que conectam o sistema axiomático com as observações [com os fatos] que os sistemas adquirem significado empírico. 
de lidar com os problemas centrais do Círculo de Viena e, ademais, depurar a Epistemologia de seus elementos psicológicos.

Para argumentar a favor de tal ponto, Carnap, de acordo com Passmore (1957, p. 379), classifica as sentenças advindas de possíveis pesquisas em três categorias: (i) sentenças-sintáticas; (ii) sentenças-objetos; (iii) sentenças pseudo-objeto. De maneira sucinta, as sentenças-sintáticas são as sentenças elaboradas em uma investigação constituída sob a égide do método sintático e elas dizem respeito às características linguísticas formais da linguagem-objeto que é investigada; as sentenças-objeto são as sentenças elaboradas nas ciências empíricas e se referem aos objetos e fenômenos estudados por essas ciências; já as sentenças pseudo-objeto caracterizam parte da Epistemologia, pois aparentemente se referem a objetos, porém, após serem depuradas, mostram-se sentenças sintáticas.

Desta forma, Carnap entende que parte da Epistemologia de sua época era formada por sentenças quasi-sintáticas que estavam mal formuladas no modo material do discurso, isto é, sentenças que, expressas na linguagem natural, aparentemente se referiam a objetos, mas que se fossem reformuladas em uma plataforma de análise adequada, ou seja, numa metalinguagem-sintática, passariam a ser sentenças sintáticas elaboradas no modo formal do discurso. Com essa tradução do modo material ao modo formal, sentenças como "a lua é um objeto; cinco não é um objeto, mas um número" se transformariam em "o termo 'lua' é um signo-objeto (nome-objeto); a palavra 'cinco' não é um signo-objeto, mas um signo-número" (CARNAP, 1937a, p. 297).

Em um nível mais intrínseco às discussões filosóficas, sentenças como, por exemplo, "um objeto é um complexo de dados dos sentidos" e "um objeto é um complexo de átomos" se transformariam, respectivamente, em "toda sentença em que uma designação de objeto ocorre é equipolente à classe de sentenças na qual ocorrem designações de dados dos sentidos" e "toda sentença em que ocorre uma designação de objeto é equipolente a uma sentença na qual ocorrem coordenadas espaço- 
-temporais e certos functores descritivos da física"17 (CARNAP, 1937a, p. 301).

Com a tradução ao modo formal do discurso, as investigações filosóficas, ora em destaque, as da Epistemologia, sairiam do campo de pesquisa ambíguo, no qual as sentenças parecem se referir a objetos físicos e fenômenos, ou seja, uma investigação sobre os objetos das ciências empíricas, mas sem os métodos e critérios científicos de avaliação, e passariam à investigação metalinguística com uma linguagem de referência estabelecida. Assim, "a tradutibilidade ao modo formal do discurso constitui a pedra de toque para todas as sentenças filosóficas, ou, de modo geral, para todas as sentenças que não pertencem à linguagem de nenhuma das ciências empíricas" (CARNAP, 1937a, p. 313, itálico do autor).

Todavia, dois pontos merecem ser destacados. O primeiro, é que o modo material não é em si mesmo errôneo, mas somente perigoso, principalmente por conta da riqueza da linguagem natural que impossibilita que ela seja utilizada enquanto um sistema de regras determinadas e precisas. Além disto, Carnap (1937a, p. 312) enfatiza que o modo material é notoriamente bem estabelecido e, de modo geral, mais simples, óbvio e compreensível que o modo formal, o que faz com que seu uso seja frequentemente expediente. Portanto, a instituição e a importância do modo formal para as discussões em Filosofia da Ciência não implicam na eliminação do modo material.

17 De modo detalhado, o critério de Carnap para a identificação de uma sentença quasi-sintática é: suponha-se que exista um domínio de objetos $O$, cujas propriedades são descritas em uma linguagem $L$, nessa linguagem existe uma propriedade $P(x)$, onde $x$ está no lugar de um objeto. Além disso, suponha-se que existe uma propriedade sintática $P^{\prime}(y)$, onde $y$ está no lugar de uma expressão. Com isto posto, para cada vez que $P$ qualificar um objeto, $P^{\prime}$ qualificar a expressão que designa aquele objeto, então $P$ ' é considerada a propriedade sintática correlacionada à $P$, e $P$, portanto, é chamada de propriedade quasi-sintática. Logo, toda vez que uma sentença designa uma propriedade quasi-sintática $P(x)$, onde x é aparentemente um objeto, esta sentença é quasi-sintática. Portanto, uma sentença quasi-sintática $S$ é uma sentença sintática mal formulada no modo material do discurso, se a tradução desta sentença para o modo formal produz uma sentença sintática $S^{\prime}$ correspondente à $S$ e pertencente à metalinguagem sintática (CARNAP, 1937a, p. 287; CIRERA, 1994, p. 253; PEREIRA, 2013, p. 60). 
O segundo ponto é que, uma vez que uma separação clara entre os elementos científicos e não científicos da Filosofia e, especialmente, da Epistemologia, não pode ser feita, Carnap assevera que "a Lógica da Ciência assume o lugar do inextricável emaranhado de problemas que é conhecido como Filosofia" (CARNAP, 1937a, p. 279, itálico do autor). Desta maneira, podemos entender a construção da Lógica da Ciência enquanto a inauguração de um campo de estudos que visa englobar os problemas que interessavam ao Círculo de Viena e que, em geral, haviam sido tratados pela Filosofia [Epistemologia]. Logo, a Lógica da Ciência, valendo-se do método formal do discurso, substitui a Filosofia no sentido de que os problemas não são mais enfrentados por um método especulativo filosófico, que acarretam indecidíveis disputas linguísticas, mas sim pelo rigor técnico-teórico de uma disciplina formal, analítica e científica.

\section{Logical Syntax: Filosofia Da Ciência e o Equívoco de Coffa}

Com nossa incursão pela elaboração da Lógica da Ciência, podemos compreender o projeto de Carnap em 1934 e a estrutura a qual Coffa (1991, p. 371) se refere quando diz "no fim, o modo formal de Carnap e o desaparecimento da certeza transformou a teoria correspondentista [da verdade] na teoria coerentista e, portanto, levou o positivismo de seu inicial prescritivismo a uma posição radicalmente descritivista"18.

Tenhamos claro, não obstante, que a interpretação de Coffa (1991, p. 354; 370-371) é a de que tal estrutura, em somatória ao abandono da certeza [status de incorrigibilidade das sentenças protocolares], junto ao antifundacionismo decorrente, levaram Carnap ao abandono da teoria correspondentis$18 \quad$ Embora não seja o foco do trabalho, na Introdução de Logical positivism (1959a), Ayer (1959, p. 20) também sustenta que Carnap adotou uma teoria coerentista da verdade: "Eles [Carnap e Neurath] estavam convictos, nesta época, que era metafísico falar da comparação de enunciados com fatos. Pois, o que essa 'comparação' poderia ser se não uma relação lógica? E a única coisa a qual um enunciado pode estar em qualquer relação lógica é outro enunciado. Consequentemente, eles foram levados a adotar uma teoria coerentista da verdade". Portanto, se mostrarmos que Carnap não adotou uma teoria coerentista em detrimento de uma teoria correspondentista, respondemos não somente Coffa, mas também esta afirmação de Ayer. 
ta da verdade e, assim, o empirismo carnapiano rompeu o elo existente entre o conhecimento e a realidade, pois transformou a questão da verdade das sentenças sintéticas em uma questão de convenção. Logo, o resultado trágico dessa cadeia, teoria coerentista da verdade, convencionalismo da base empírica e relativismo epistemológico.

Para que possamos entender tal crítica, é preciso que os pontos elencados, com suas inter-relações, estejam claros. Deste modo, estipulemos algumas definições, enquanto discutimos tais questões, com vistas a apreciá-las devidamente. Comecemos por fundacionismo:

Definição 1.1: Uma teoria ou sistema caracteriza-se como fundacionista quando: (a) define um conjunto de enunciados básicos irrevisáveis; (b) mostra como construir e reduzir os demais enunciados científicos a partir destes enunciados irrevisáveis (HAACK, 1993, p. 14; LISTON, 2015, p. 130).

Com essa definição, vemos que a alteração do status de incorrigibilidade das sentenças protocolares, uma vez que essas sentenças ocupam o lugar das sentenças básicas na reconstrução racional do conhecimento científico, acarreta no abandono do fundacionismo. Especificamente, quando Carnap (1937a, p. 318), em Logical syntax, assevera que nenhuma sentença está imune à revisão no sistema, por definição, seu sistema não pode ser fundacionista.

Tentemos entender, agora, a posição de Coffa: em um sistema fundacionista como o do Aufbau, o elo ocorre pelo fato das sentenças básicas possuírem seu valor de verdade determinado por meio de uma teoria correspondentista da verdade, que pode ser definida da seguinte forma:

Definição 2.1: Uma teoria da verdade é correspondentista quando sustenta que a verdade de uma sentença consiste na relação de correspondência desta com o mundo, isto é, com os fatos (HAACK, 2002, p. 127). 
Com as sentenças básicas expressas em uma linguagem fenomenalista, isto é, em uma linguagem de descrições das experiências perpetuais, do imediatamente dado na experiência, Coffa entende que as sentenças básicas não só recebem seu status de verdadeira pela correspondência com os fatos, mas gozam de um status epistemologicamente privilegiado por descreverem os dados dos sentidos e, consequentemente, serem certas e irrevisáveis ${ }^{19}$. Assim, quando Carnap (1937a, p. 318; 320) adere ao falibilismo, que pode ser definido, informalmente, como a posição de que nenhum sistema, teoria ou sentença está imune à revisão, e, consequentemente, assevera que mesmo uma sentença protocolar pode ser rejeitada, Coffa considera que Carnap torna toda a questão da verdade das sentenças sintéticas uma questão de convenção.

A situação, na perspectiva de Coffa, pode ser sumariada assim: com o aspecto convencional e com a possibilidade de erro na base empírica e sem o "solo" seguro das sentenças protocolares irrevisáveis, o link do conhecimento com a realidade é perdido. É por conta disso que Coffa entende que Carnap abre mão, também, da teoria correspondentista da verdade em detrimento de uma teoria coerentista, que, por sua vez, pode ser definida da seguinte forma:

Definição 2.2: Uma teoria da verdade é coerentista quando sustenta que a verdade das sentenças consiste nas relações de coerência interna em um conjunto de sentenças e em dado sistema linguístico (HAACK, 2002, p. 127).

Não obstante, Coffa (1991, p. 367) entende, assim como Schlick já considerava em suas discussões no Círculo de Viena, que uma teoria coerentista ignora a importância da experiência na construção do sistema de conhecimento científico e, desta maneira, remove o agente regular do conhecimento:

$19 \quad$ Vale lembrar que o salto da "certeza" é feito por Coffa, o sistema fundacionista do Aufbau é de método, e não de base. 
Com o auxílio da fantasia posso pintar um mundo grotesco e cheio de aventuras: o filósofo adepto da coerência deve crer na verdade da minha descrição se eu tiver o cuidado de evitar contradição entre as minhas afirmações e, como medida de precaução, evitar toda contradição com a habitual descrição do mundo, o que é possível transferindo o cenário da minha descrição para um astro remoto onde qualquer observação é impossível. A rigor, tal medida de precaução nem sequer é necessária, pois posso exigir que os outros aceitem a minha descrição, e vice-versa. Os outros não poderão objetar, por exemplo, que este método contradiz as observações, pois segundo a teoria da coerência, são absolutamente irrelevantes quaisquer observações, interessando apenas a inexistência de contradição entre as afirmações (SCHLICK, 1975, p. 77).

Portanto, a análise de Coffa sobre o movimento carnapiano em Logical syntax, por fim, é a seguinte: se não há nenhuma sentença com status epistemologicamente privilegiado, se existe convencionalidade na aceitação das sentenças protocolares e se a verdade de uma sentença depende apenas de sua coerência com um conjunto de sentenças aceitas previamente, então o componente objetivo que advém da experiência, do teste empírico, é perdido por completo: "apesar de toda criatividade, inspiração e convenção que envolve o ato da experiência, ainda existe algo que é imposto a mim. Mas, este algo, a realidade, desapareceu por completo quando Carnap e Neurath fizeram suas ascensões sintáticas" (COFFA, 1991, p. 370). Com isto posto, o resultado trágico dessa "escalada" é o convencionalismo da base empírica e, como Coffa considera, relativismo epistemológico ${ }^{20}$.

Com a crítica de Coffa esmiuçada, vejamos se, de fato, ela se aplica às construções e posições de Carnap em Logical syntax. No texto de 1934, as posições metateóricas de Carnap aparecem em uma breve análise lógica que o autor promove acerca da Física, ou seja, dentro da estrutura sintática elaborada, "a análise lógica da Física - enquanto parte da Lógica da Ciência - é a sintaxe da linguagem fisicalista" (CARNAP, 1937a, p. 315). É a esta análise que nos dedicaremos agora.

20 Relativismo epistemológico é entendido aqui em sentido pejorativo, significando, na visão de Coffa, que, uma vez adotadas as posições de convencionalismo da base empírica e teoria coerentista da verdade, qualquer coisa valeria como conhecimento científico desde que o sistema apresentado fosse coerente internamente e acordado entre uma comunidade. 
Definida que a linguagem-objeto é a linguagem fisicalista, o primeiro passo da análise lógica, segundo Carnap (1937a, p. 316), é estabelecer regras de formação para as sentenças e expressões desta linguagem. Estipuladas tais regras, as sentenças podem ser classificadas de acordo com seus respectivos graus de generalidade e, nos extremos, teríamos, de acordo com o autor, dois tipos de sentenças: (i) as concretas, que não contém variáveis irrestritas como argumentos, como, por exemplo, "existe um pé de amora no quintal de Larissa às 15:00h no dia 23 de março de 2020"; (ii) as leis, que não possuem constantes como argumentos, tal como, "todo corpo continua em seu estado de repouso ou de movimento uniforme em uma linha reta, a menos que seja forçado a mudar aquele estado por forças aplicadas sobre ele".

Com as regras de formação estabelecidas, o passo seguinte é determinar as regras de transformação. No que diz respeito a estas, Carnap (1937a, p. 316) sustenta que tanto regras lógicas, quanto regras lógicas em conjunto a regras físicas podem ser dadas como as regras de transformação da linguagem fisicalista. Além disso, o autor destaca que se optarmos por utilizar regras físicas, elas podem ser elaboradas na forma de sentenças físicas primitivas e que, pela tendência geral de escolher leis universais para tal papel, elas são chamadas de leis primitivas ${ }^{21}$.

Prescritas essas diretrizes que estabelecem como, de modo geral, proceder com a análise lógica, uma das primeiras afirmações de Carnap (1937a, p. 317) é a de que:

Uma sentença da Física, seja ela uma sentença P-primitiva [lei primitiva], seja ela alguma outra sentença válida, seja ela uma suposição indeterminada (isto é, uma premissa cujas consequências estão no percurso de investigação), será testada através da dedução de consequências por meio das regras de transformação, até que essas consequências alcancem a forma de sentenças protocolares. Estas serão, então, comparadas com as sentenças protocolares que já foram estabelecidas e serão confirmadas ou rejeitadas com base nelas (CARNAP, 1937a, p. 317).

$21 \quad$ Carnap (1937, p. 316) assevera que as leis podem ter tanto caráter determinístico, quanto probabilístico. 
Considerando que sentenças protocolares são relatórios de observação produzidos pelos cientistas, fica difícil sustentar, diante dessa passagem, que Carnap excluiu o componente objetivo do teste empírico em sua reconstrução racional do conhecimento científico. Contudo, a posição de Coffa (1991, p. 371) é a de que o aspecto convencional envolvido nos diversos registros deste processo é que rompem a ligação das sentenças sintéticas com a realidade.

O primeiro aspecto convencional que aparece na análise de Carnap, após as escolhas das regras de formação e transformação, diz respeito à forma que as sentenças protocolares terão, isto é, regras sintáticas devem ser estabelecidas estipulando qual a forma das sentenças protocolares, como, por exemplo, se elas serão escritas em linguagem fenomenalista ou fisicalista. Nesta breve discussão, Carnap (1937a, p. 317) afirma que:

[...] não é tarefa da sintaxe determinar quais sentenças, da forma protocolar estipulada, serão de fato estabelecidas como as sentenças protocolares, pois 'verdade' e 'falsidade' não são termos sintáticos; a determinaçã̃o das sentenças protocolares é assunto do físico que está fazendo as observações e produzindo os protocolos.

Com essa passagem, que é tudo que Carnap fala diretamente acerca da temática da teoria da verdade na análise da Física, conseguimos fazer uma primeira contraposição à interpretação de Coffa. Com efeito, por um lado, Carnap não apresenta, explicitamente, uma teoria correspondentista na análise da linguagem fisicalista pelo fato de que ele não a sustenta clara e manifestamente. Porém, por outro, Carnap não adere, tampouco, uma teoria coerentista da verdade. Ele não faz nenhuma adesão explícita nessa matéria, pois não pode, Carnap considera os termos "verdade" e "falsidade" fora do escopo sintático na qual a Lógica da Ciência é elaborada. Por esta razão, aderir explicitamente uma teoria da verdade, na análise lógica sintática, é trair o projeto sintático e, claro, o programa da Lógica da Ciência.

No entanto, insistamos que a posição de Coffa é a de que a adesão à teoria coerentista é uma consequência do convencionalismo carnapiano e do abandono da infalibilidade epistemológica das sentenças protocolares. Deste modo, sus- 
tentar que Carnap não adere explicitamente nenhuma teoria da verdade não seria suficiente para defender o empirismo carnapiano das críticas de Coffa. Portanto, voltemos nossa atenção ao cerne da discussão para Coffa.

A falibilidade epistemológica aparece no momento em que Carnap (1937a, p. 317) assevera que, no teste de uma sentença e diante de uma contradição entre a sentença deduzida e as sentenças protocolares previamente estabelecidas, qualquer alteração pode ser feita no sistema. Explicitamente, Carnap (1937a, p. 317) sustenta que as regras físicas e lógicas podem ser alteradas para invalidar a dedução, assim como as sentenças protocolares podem ser descartadas, "não há nenhuma regra estabelecida para o tipo de mudança que deve ser feita". Consequentemente, não há nada de sacrossanto no sistema, as sentenças protocolares são revisáveis, assim como as leis da Física e da Matemática, "nenhuma regra da linguagem fisicalista é definitiva; todas as regras são estipuladas com a reserva de que elas podem ser alteradas assim que parecer expediente fazer" (CARNAP, 1937a, p. 318).

Quanto ao convencionalismo, ele aparece, por exemplo, quando Carnap (1937a, p. 320, itálico do autor) proclama que "a construção do sistema da Física não é feita de acordo com regras definidas, mas por meio de convenções". Porém, ainda que a escolha das regras seja convencional, isto não implica que elas sejam escolhidas de maneira arbitrária, valendo qualquer coisa. A escolha destas regras, sustenta Carnap (1937a, p. 320), é guiada, em uma instância, por considerações metodológicas, como simplicidade, conveniência e fecundidade e, em outra instância, pelo fato de que "[...] as hipóteses podem e devem ser testadas pela experiência, isto significa dizer, pelas sentenças protocolares - tanto aquelas que já estão estabelecidas, quanto as novas que estão constantemente sendo adicionadas no sistema".

Contudo, o teste, a rigor, não é definitivo, pois, consideremos, como Carnap (1937a, p. 317-318) faz, uma lei científica, esta nunca pode ser univocamente determinada pelas sentenças protocolares, pois, em virtude da sua irrestrita universalidade, seu conteúdo lógico vai além do conteúdo de 
qualquer classe finita de sentenças protocolares, logo, as leis possuem caráter de hipóteses. Além disso, como o autor ainda destaca, mesmo as sentenças protocolares possuem o caráter hipotético, devido a constante possibilidade de erros. Desta maneira, Carnap nos atenta para o fato de que no conhecimento científico dois aspectos caminham juntos, o aspecto objetivo do teste empírico, e o aspecto convencional, como, por exemplo, o da escolha da linguagem para a ciência e o de quando parar os testes e considerar uma hipótese suficientemente confirmada.

Desta forma, quando Coffa (1991, p. 354) alega que a posição de Carnap em Logical syntax apresenta uma imagem mais razoável da função da certeza no conhecimento científico, nós concordamos com ele, a saber, não há papel para a certeza no conhecimento científico. No entanto, devemos admitir, seguindo Coffa (1991, p. 354), que a conclusão carnapiana acerca da certeza implica no desaparecimento do componente objetivo advindo da experiência? Nossa resposta é não, Carnap (1937a, p. 318) assevera explicitamente que as leis, assim como todas sentenças empíricas no sistema científico, são sempre selecionadas e estipuladas sobre as bases das sentenças protocolares previamente estabelecidas e que essas são constantemente reexaminadas através de novas sentenças protocolares que surgem a todo instante no empreendimento científico.

Não obstante, devemos sempre salientar que as sentenças protocolares, mesmo na linguagem fisicalista, preterida por Carnap ao adotar a tese do fisicalismo junto a Neurath, são relatórios de observação como, por exemplo, "há três cadernos e uma lapiseira sobre a mesa de Larissa às 22:00h do dia 23 de março de 2020". Sendo assim, as sentenças protocolares têm como substrato o teste empírico, a experiência e, se Carnap não diz explicitamente que elas se referem, em última instância, aos fatos, em sua análise da Física, isto se deve à estrutura sintática restrita na qual ele estava trabalhando, isto é, valendo-se do modo formal do discurso, em Logical syntax, Carnap não pode fazer nenhuma referência extralinguística. Porém, quando Carnap discutiu, neste mesmo texto, no modo material, ele afirmou que: 
Uma sentença sintética é as vezes verdadeira - especificamente, quando certos fatos existem - e as vezes falsa; portanto diz algo sobre quais fatos existem. As sentenças sintéticas são os genuínos enunciados sobre a realidade (CARNAP, 1937a, p. 41, itálico do autor).

Isto posto, a posição antifundacionista de Carnap não implica, como Coffa proclama, no abandono do correspondentismo e no relativismo epistemológico. A base empírica, em seu sistema, é sim convencional, mas, para nos remetermos a uma metáfora bastante conhecida ${ }^{22}$, o navio do empirismo carnapiano não levantou âncora do solo da experiência, as sentenças sintéticas continuaram a ser confrontadas com o mundo empírico. O que Carnap defendeu, em Logical syntax, é que o resultado desse confronto nunca é uma certeza intocável, como queriam os fundacionistas mais fervorosos, como Schlick ${ }^{23}$.

Portanto, devemos aferir, em detrimento à posição de Coffa, que Carnap, em Logical syntax, não só apresentou uma representação mais razoável do papel da certeza no conhecimento científico, mas que, também, apresentou uma imagem mais razoável do próprio conhecimento científico. Se, como Carnap (1937a, p. 318) salienta, nós não podemos, em sentido estrito, nem refutar, nem confirmar, de uma vez por todas, nossas hipóteses ${ }^{24} \mathrm{e}$, se, nosso conhecimento é, no melhor dos

$22 \quad$ "Não há nenhuma maneira de tomar sentenças protocolares puras e conclusivamente estabelecidas como ponto inicial das ciências. Nenhuma tabula rasa existe. Nós somos como marinheiros que devem reconstruir seu navio em mar aberto, sem nunca o desmontar em uma doca seca e reconstruí-lo a partir dos melhores materiais. Apenas os elementos metafísicos podem desaparecer sem deixar rastros. Conglomerados linguísticos vagos sempre irão permanecer, de uma maneira ou de outra, como componentes do navio. Se a vagueza é diminuída em um ponto, ela pode muito bem aumentar em outro" (NEURATH, 1959, p. 201, itálico do autor).

$23 \quad$ Para Schlick (1975, p. 86), as sentenças básicas no sistema científico são o que ele chamou de "constatações", proposições na linguagem fenomenalista do tipo "aqui agora é azul", cujo sentido só é compreendido se confrontada com os fatos, que quando registradas por escrito perdem o sentido e que, não obstante, são revestidas de absoluta realidade [certeza].

$24 \quad$ Como as leis, as sentenças concretas e os protocolos são considerados como hipóteses e como não há confirmação definitiva destas, logo, Carnap, em Logical syntax, abandona o verificacionismo e passa ao confirmacionismo. Questão que será discutida, e posição que ficará clara, em "Testability and meaning" (1936/37). 
casos, falível, estas são condições que se mostraram intrínsecas ao conhecimento humano e que nenhuma filosofia ou ciência, até hoje, conseguiu superar.

Por último, indiquemos as posições carnapianas em todos os registros que foram discutidos de maneira interligada, com vistas à clareza e à leitura textualmente consistente que prometemos no início. Em Logical syntax: (i) o sistema carnapiano é do tipo falibilista; (ii) não há adesão explícita a nenhuma teoria da verdade, embora o aspecto correspondentista se faça presente através da necessidade do teste empírico [confronto com os fatos] de toda e qualquer sentença sintética; (iii) as sentenças protocolares são revisáveis, não há nada de sacrossanto no sistema; (iv) a base empírica é convencional; (v) não há relativismo epistemológico, a despeito de todo convencionalismo, o componente factual e objetivo está sempre presente guiando e regulando as construções.

\section{Considerações Finais}

Um ponto que pode explicar o equívoco da interpretação de Coffa é o não reconhecimento daquilo que é o convencional e daquilo que é factual na abordagem carnapiana em Logical syntax $^{25}$. O convencionalismo de Carnap (1937, p. 51, itálico do autor), expresso no princípio de tolerância: "não é nosso

$25 \quad$ Salientamos que este é um ponto, pois é possível atribuir o equívoco a outras considerações, como, por exemplo, a associação que Coffa faz entre as posições de Carnap e Neurath. É um fato que as posições de Neurath foram fundamentais nas transformações da obra carnapiana, primeiro na adesão da tese fiscalista para unidade da ciência, isto em 1932 em The unity of science (1995), depois no abandono do fundacionismo em Logical syntax. Contudo, como nota Uebel (2019, p. 4), as perspectivas dos membros do Círculo de Viena podem ser tão distintas que mesmo os pontos concordantes não podem ser considerados de maneira inquestionável. Este é o caso entre Neurath e Carnap, conhecidos não só como membros do Círculo de Viena, mas da left wing, deste. Não obstante, a interpretação que Coffa faz de Neurath, prima facie, consideramos equivocada. Assim, não só a associação é injustificada, como ela se basearia em uma posição errônea sobre a obra de Otto Neurath. 
trabalho estabelecer proibições, mas chegar a convenções."26, diz respeito, como nota Liston (2015, p. 124-125), à liberdade de escolha das estruturas linguísticas, como, por exemplo, das regras de formação e transformação, da forma das sentenças protocolares, etc ${ }^{27}$. Ademais, ainda que a base empírica seja convencional, o convencionalismo carnapiano nunca define o conteúdo das sentenças sintéticas, os enunciados básicos sempre são confrontados com os fatos.

Assim, ao contrário do que Coffa alega, Carnap estaria em pleno acordo quando este diz:

A experiência, objetivamente construída, é um processo que envolve uma grande carga de atividade humana e convenção, mas também envolve algo mais. Nós podemos ou não ter os conceitos necessários para formular conjecturas eletromagnéticas; nós podemos escolher abrir nossos olhos em frente ao voltímetro ou não. Mas, se nós fizermos todas estas coisas, nós não somos mais livres para escolher ver a agulha do voltímetro apontando o número 4 (COFFA, 1991, p. 366)

Consequentemente, Carnap não tornou a questão da verdade das sentenças sintéticas uma questão de convenção, a experiência no empirismo carnapiano, como na tradição que Coffa (1991, p. 354) alega que Carnap rompe, continuou funcionando como o substrato último de toda justificação empírica e como a pedra de toque para o link entre nosso conhecimento e a realidade. O que Carnap negou, de fato, é que esse substrato, descrito nas sentenças protocolares, representa uma base "certa" e incorrigível. Portanto, o que Carnap abriu mão, em Logical syntax, foi do fundacionismo, em detrimento do falibilismo epistemológico.

26 A continuação da formulação do Princípio, relembremos, é a seguinte: "em Lógica, não há moral. Cada um é livre para construir sua própria lógica, isto é, sua própria forma de linguagem, como quiser. Tudo que é requerido deste indivíduo é que, se ele deseja a discutir conosco, ele deve estabelecer seus métodos claramente, e dar regras sintáticas [lógicas], ao invés de argumentos filosóficos" (CARNAP, 1937a, p. 52, itálico do autor).

27

A escolha da linguagem da ciência é uma questão convencional, isto vale tanto a nível teórico, quanto metateórico, ou seja, os cientistas gozam da liberdade de escolher suas estruturas linguísticas, assim como os lógicos da ciência gozariam da liberdade de escolher suas estruturas para reconstruir racionalmente o conhecimento científico. 
Já a última crítica que devemos tratar, é aquela em que Coffa (1991, p. 371) assevera que o modo formal de Carnap, em somatória ao abandono da certeza, levaram o Empirismo Lógico, do seu prescritivismo inicial, a uma posição radicalmente descritivista. Desta maneira, nossa última questão é: com a Lógica da Ciência no lugar da Epistemologia e com o falibilismo epistemológico no lugar do fundacionismo, Carnap abandonou o prescritivismo e adotou um descritivismo radical?

Enquanto a Lógica da Ciência substitui a Epistemologia e, portanto, aquela formulação lógico-psicológica do papel da Filosofia na justificação do conhecimento é perdida ${ }^{28}$, é um fato que a Lógica da Ciência é elaborada com vistas a incorporar problemáticas da Epistemologia. Assim, ainda que abandonado o aspecto psicológico da investigação, a questão de justificar racionalmente o conhecimento científico continuou uma preocupação constante na obra carnapiana, como pode ser visto em diversos textos, tais como "Testability and meaning" (1936/37), onde é discutida a proposta empirista para a linguagem da ciência, Logical foundations of probability (1963a), onde Carnap tenta construir uma lógica indutiva com vistas a explicar racionalmente os processos indutivos da ciência e "O caráter metodológico dos conceitos teóricos" (1975a), onde Carnap explicitamente sustenta que um conceito teórico só tem significado empírico se correlacionado, adequadamente, a conceitos observacionais. Em resumo, os aspectos do normativismo carnapiano sempre estiveram presentes em seus critérios de cientificidade e na busca incessante de justificação lógico-racional para os procedimentos indutivos, tão utilizados na prática científica.

No entanto, o que Coffa parece interpretar é que uma posição normativista tem de ser fundacionista. Mas, como Dutra (2017, p. 181-182) salienta, enquanto o sistema fundacionista representa o que poderíamos chamar de "estandarte" da posição normativa, pois ele prescreve, claramente, as condições de possibilidade do conhecimento e, deste modo, o que o cientista deve respeitar se quiser fazer ciência, há posições nor-

$28 \quad$ Lembremos que em Pseudoproblemas na Filosofia (1975b), Carnap (1975b, p. 149) escreve, "o objetivo da epistemologia é a formulação de um método para a justificação das cognições (Erkenntnisse)". 
mativas que não provém a ciência com fundamentos seguros. Conquanto o exemplo que Dutra (2017, p. 182) utiliza para asseverar este ponto é o do Popper em A lógica da pesquisa científica (2013), por conta da posição falibilista e do seu falseacionismo metodológico como critério de cientificidade, o exemplo poderia muito bem ser o de Carnap antifundacionista. Desta forma, é outro equívoco de Coffa a alegação de que Carnap transformou o prescritivismo inicial do Empirismo Lógico em uma plataforma completamente descritivista.

Logo, a depuração da Epistemologia, que em Logical syntax acarreta no abandono desta em detrimento da Lógica da Ciência, não implica no abandono do prescritivismo, das preocupações justificacionistas do conhecimento científico. Especialmente porque, como citamos, com o projeto da sintaxe lógica, Carnap pretende a inauguração de um campo de estudos que englobaria os problemas que interessavam diretamente ao Empirismo Lógico e que foram tradicionalmente tratados pela Filosofia [Epistemologia], muitas das vezes de maneira especulativa ou invadindo o campo das ciências especiais, como o da Psicologia. Assim, o projeto da Lógica da Ciência visava que as questões centrais do Empirismo Lógico e, de modo geral, da Filosofia da Ciência, fossem investigadas por meio de uma estrutura lógico-linguística, isto é, por um método formal e científico, e não por especulação filosófica. Este é o projeto da filosofia científica de Carnap.

Tal projeto, como Liston (2015, p. 186) já apontou, assenta-se na perspectiva carnapiana de que só há dois tipos de proposições significativas, as analíticas e as empíricas, cabendo exclusivamente às ciências especiais a tarefa de investigar os fatos da natureza e produzir as sentenças sintéticas, de modo que à Lógica da Ciência cabe a análise metalinguística dessas sentenças. Portanto, o que resta para a Filosofia da Ciência é a análise lógica da linguagem das ciências especiais, ou, então, da ciência unificada. Em resumo, o que resta é um método, o método da análise lógica. Método este que, não obstante, foi matéria de constante transformação na obra carnapiana, passando da plataforma construcional do Aufbau, à plataforma sintática de Logical syntax e, posteriormente, por influência dos 
avanços de Tarski no campo da semântica ${ }^{29}$, foi incrementado com a semântica. Isto mostra que Carnap nunca pretendeu um sistema definitivo, mas que, guiado pela posição empirista, plural e tolerante, sempre procurou reelaborar seu sistema diante das dificuldades, possibilidades e avanços que surgiram.

\section{Referências Bibliográficas}

AWODEY, S. \& CARUS, A. W. "From Wittgenstein's prison to the boundless ocean: Carnap's dream of Logical syntax". In: WAGNER, P. (ed.). (2009). Carnap's logical syntax of language. Houndmills, et al.: Palgrave Macmillan, 2009.

AYER, A. J. Editor's Introduction. In: AYER, A. J. (ed.). (1959a). Logical positivism. New York: The Free Press, 1959.

AYER, A. J. Language, truth and logic. London: Penguin Group, 1971.

AYER, A. J. (ed.). Logical positivism. New York: The Free Press, 1959a.

CARNAP, R. "Da epistemologia à lógica da ciência". Tradução de Gilson Olegario da Silva. Disputatio. Vol. 1, No. 1, 2012: p. 131-135.

CARNAP, R. "Empirismo, semântica e ontologia". Tradução de Pablo Rubén Mariconda. Os Pensadores. São Paulo: Abril Cultural, 1975.

CARNAP, R. "Intellectual Autobiography". In: SCHILPP, P. A. (ed.) (1963). The philosophy of Rudolf Carnap. La Salle: Open Court, 1963.

CARNAP, R. "O caráter metodológico dos conceitos teóricos". Tradução de Pablo Rubén Mariconda. Os Pensadores. São Paulo: Abril Cultural, 1975a.

CARNAP, R. Logical foundations of probability. Chicago: The University of Chicago Press, 1963a.

CARNAP, R. "On protocol sentences". Noûs. Vol. 21, No. 4, 1987: p. 457-470.

CARNAP, R. "Pseudoproblemas na Filosofia". Tradução de Pablo de Rubén Mariconda. Os Pensadores. São Paulo: Abril Cultural, 1975b.

CARNAP, R. "Testability and meaning". Parte 1. Philosophy of Science, Vol. 3, No. 4, 1936: p. 419-471.

$29 \quad$ O marco destes avanços, do ponto de vista da obra carnapiana, é o texto "O conceito de verdade nas linguagens formalizadas" (2007), onde Tarski elabora uma definição de verdade que é materialmente adequada, formalmente correta e em uma plataforma semântica. 
CARNAP, R. "Testability and meaning". Parte 2. Philosophy of Science, Vol. 4, No. 1, 1937: p. 1-40.

CARNAP, R. The logical structure of the world. Translated by Rolf A. George. California: University of California Press, 2005.

CARNAP, R. The logical syntax of language. Reimpressão (2017), India: Facsimile, Publisher, 1937a.

CARNAP, R. The unity of science. Translated by M. Black. Bristol: Thoemmes Press, 1995.

CARUS. A. W. Carnap and twentieth-century thought. Cambrigde: Cambridge University Press, 2009.

CIRERA, R. Carnap and the Vienna circle. Translated by Dick Edelstein. Amsterdam \& Atlanta: Editions Rodopi B. V.., 1994.

COFFA, J. A. The semantic tradition from Kant to Carnap: to the Vienna Station. Cambridge: Cambridge University Press, 1991.

DUTRA, L. H. A. Introdução à teoria da ciência. Florianópolis: Editora da UFSC, 2017.

FEIGL, H. "A visão 'ortodoxa' de teorias: comentários para defesa assim como para crítica". Tradução de Osvaldo Pessoa Júnior. Scientiae studia. São Paulo, Vol. 2, 2004, p. 265-277.

FAJARDO, R. A. S. Lógica Matemática. São Paulo. Editora da Universidade de São Paulo, 2017.

GÖDEL, K. Collected Works. Edited by Solomon Feferman, et al. Vol. 1. New York: Oxford University Press / Oxford: Clarendon Press, 1986.

HAACK, S. Filosofia das lógicas. Tradução de Cezar Augusto Mortari e Luiz de Araújo Dutra. São Paulo: Editora Unesp, 2002.

HAACK, S. Evidence and inquiry: towards reconstruction in Epistemologi. Oxford, et al.: Blackwell, 1993.

LISTON, G. Carnap: lógica, linguagem e ciência. Campinas: Editora PHI, 2015.

NEURATH, O. Philosophical papers. Edited and Translated by Robert S. Cohen and Marie Neurath. Dordrecht: D. Reidel Publishing Company, 1983.

NEURATH, O. "Physicalism". In: NEURATH, O. (1983). Philosophical papers. Edited and Translated by Robert S. Cohen and Marie Neurath. Dordrecth: D. Reidel Publishing Company, 1983a.

NEURATH, O. "Physicalism: the philosophy of the viennense circle". In: NEURATH, O. (1983). Philosophical papers. Edited and Translated by Robert S. Cohen and Marie Neurath. Dordrecth: D. Reidel Publishing Company, 1983b. 
NEURATH, O. "Protocol Sentences". In: AYER, A. J. (ed.). (1959a). Logical positivism. New York: The Free Press, 1959.

PASSMORE, J. A hundred years of Philosophy. Reimpressão (1970). Harmondsworth: Penguin Books, 1957.

PEREIRA, R. A análise sintática e semântica da linguagem segundo Rudolf Carnap e Alfred Tarski. Tese (doutorado em Filosofia). Universidade Federal de São Carlos. São Carlos, 2013, 161p.

POPPER, K. A lógica da pesquisa científica. Tradução de Leonidas Hegenberg e Octanny Silveira da Mota. São Paulo: Editora Cultrix, 2013.

QUINE, W. V. O. De um ponto de vista lógico: nove ensaios lógico-filosóficos. Tradução de Antonio Ianni Segatto. São Paulo: Editora Unesp, 2011.

QUINE, W. V. O. "Dois dogmas do empirismo". Tradução de Antonio Ianni Seggato. In: QUINE, W. V. O. (2011). De um ponto de vista lógico. São Paulo: Editora Unesp, 2011a.

QUINE, W. V. O. "Epistemologia naturalizada". Tradução de Andréa Maria Altino de Campos Loparic. Os Pensadores. São Paulo: Nova Cultural, 1989.

SCHLICK, M. "O fundamento do conhecimento". Os Pensadores. São Paulo: Abril Cultural, 1975.

TARSKI, A. "O conceito de verdade nas linguagens formalizadas". Tradução de Cezar A. Mortari. In: DUTRA, L. H. A \& MORTARI, C. A. (orgs.) (2007). A concepção semântica da verdade: textos clássicos de Tarski. São Paulo: Editora UNESP, 2007.

TRANJAN, T. Carnap e a natureza da lógica. Tese (doutorado em Filosofia). Universidade de São Paulo. São Paulo, 2010, 264p.

WITTGENSTEIN, L. Tractatus logico-philosophicus. Translated by C. K. Ogden. Reimpressão (2016), New York: Dover Publications, 1922. 